\title{
Osteoporosis in the aging male: Treatment options
}

\author{
Stephen P Tuck' \\ Harish K Datta ${ }^{2}$ \\ 'Departments of Rheumatology, James \\ Cook University Hospital, Marton \\ Road, Middlesbrough, Cleveland, UK; \\ ${ }^{2} \mathrm{School}$ of Clinical and Laboratory \\ Sciences, The Medical School, \\ University of Newcastle, Newcastle \\ upon Tyne, UK
}

\begin{abstract}
In elderly women, loss in bone mass and micro-architectural changes are generally attributed to the onset of menopause. Men do not experience menopause, they do, however, experience age-related acceleration in bone loss and micro-architecture deterioration. The incidence of osteoporotic fractures in elderly men, just as in aged women, increases exponentially with age; the rise in men, however, is some 5-10 years later than in women. Up to $50 \%$ of male osteoporotics have no identifiable etiology; however elderly males have much higher likelihood of having an identifiable secondary cause than younger men. Therefore, clinical and laboratory evaluation of aged male osteoporotics must be thorough and should be aimed at identifying lifestyle or conditions contributing to bone loss and fragility. It is essential to identify and treat secondary causes and ensure adequate vitamin $\mathrm{D}$ and calcium intake before embarking upon treatment with pharmacological agents. The evidence from a limited number of trials suggests that bisphosphonates, especially alendronate and risedronate, are effective in improving BMD, and seem to be the treatments of choice in aged men with osteoporosis. In cases where bisphosphonates are contra-indicated or ineffective, teriparatide or alternatives such as strontium should be considered.
\end{abstract}

Keywords: male osteoporosis, bone mineral density, fracture risk, bisphosphonates, PTH

\section{Background}

Osteoporosis is a skeletal disorder characterized by compromised bone strength, predisposing a person to an increased risk of fracture (NIH 2000). There is a loss of bone mass and micro-architectural deterioration of bone tissue, resulting in low bone mineral density (BMD). This, in combination with other structural changes, causes an alteration in biomechanical properties and an increased risk of low trauma fractures. Osteoporosis is a common condition that afflicts both men and women, with the lifetime risk of fracture at the age of 50 years being estimated at $50 \%$ for women and $20 \%$ for men (Van Staa et al 2001; USDHHS 2004). Up to 20\% of symptomatic vertebral fractures, $25 \%$ of forearm fractures and $30 \%$ of hip fractures occur in men (Eastell et al 1998; O'Neill et al 2001; Van Staa et al 2001). Furthermore, these fractures have a profound impact on the individual in terms of morbidity and mortality (Poor et al 1994, 1995; Center et al 1999; Scane et al 1999; O’Neill et al 2001; Van Staa et al 2001).

The number of men presenting with these fractures is rising, because of increasing life expectancy and a doubling of the age specific incidence of fractures over the past three decades (Boyce and Vassey 1985; Obrant et al 1989; Royal College of Physicians 1989). Therefore, osteoporosis in men is a major health issue and so insights into its pathogenesis as well as strategies to prevent and treat it are of importance. Despite this, male osteoporosis is both under diagnosed and under treated. In a retrospective case-control study in the USA of 1,171 men with osteoporotic fractures, Feldstein et al found that only $7.1 \%$ received medication for osteoporosis and $1.1 \%$ had bone mineral measurement (Feldstein et al 2005). Kiebzak et al (2002) found similar results in men sustaining low trauma hip fractures, although the rate of treatment did rise to $27 \%$ between 1 and 5 years later. 
Low BMD is an established risk factor for osteoporotic fractures. The attainment of peak BMD and subsequent maintenance is influenced by genetic, endocrine and environmental factors. The peak bone mass is attained in the second decade of life and is followed by a period of consolidation lasting 5 years, such that peak BMD is achieved in the early to mid twenties and maintained until around the age of 40 years. Men have larger bones and hence a 10\%-12\% greater peak mass than women. After the age of 35-40 years there is a gradual loss of BMD. Women have a rapid phase of bone loss following the menopause. Men do not experience menopause, but they too undergo age-related bone loss. Therefore, advancing age is one of the most important risk factors for osteoporotic (low trauma) fractures.

\section{Epidemiology of male osteoporosis}

The major osteoporotic fractures are those of the vertebral body, hip and forearm, but fractures of the humerus, tibia, pelvis and ribs are also common. The incidence of most of these fractures rises steeply with age in both sexes (Johansen et al 1997), but the increase occurs earlier in women than

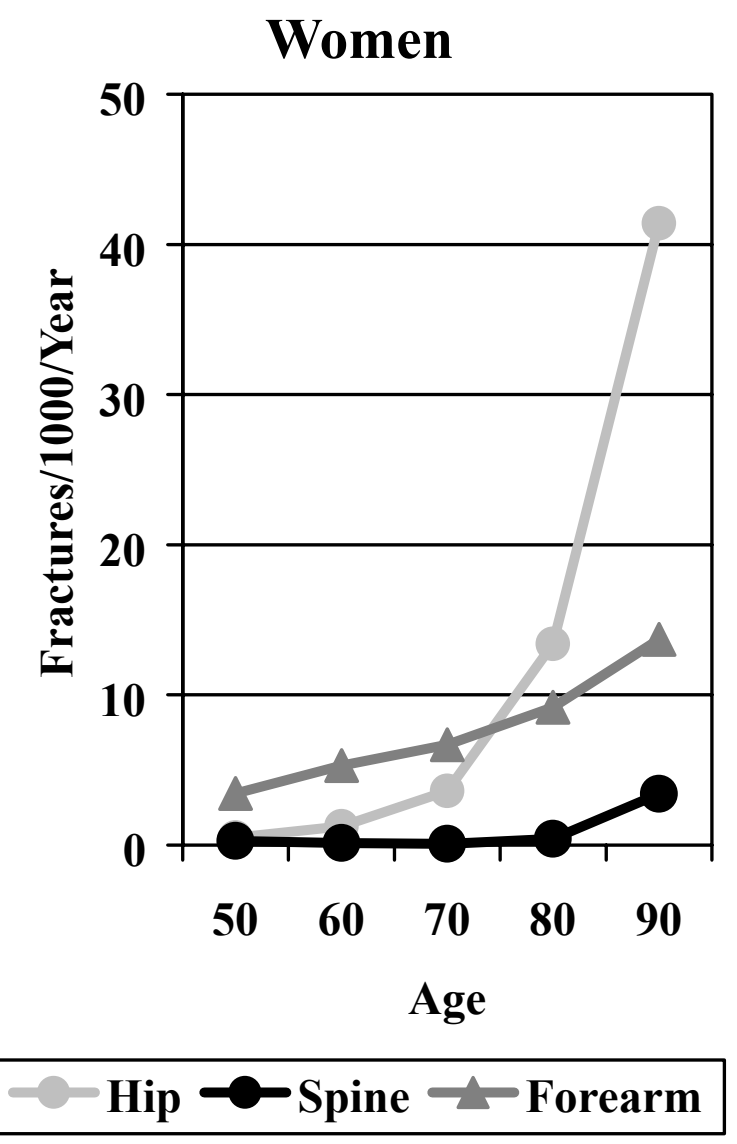

men, such that the fracture rate in elderly women is twice that of men of the same age (Figure 1).

It has been estimated that as few as 1 in 4 vertebral fractures are clinically recognised (Ensrud et al 1999). Some are asymptomatic, but it can also be difficult to distinguish a vertebral fracture from other causes of back pain and vertebral damage including: trauma, degenerative changes, Scheuermann's disease, congenital anomalies, neoplasia, infection and Paget's disease. Furthermore, there are a variety of terms and classification systems used with the expressions vertebral fracture, osteoporotic collapse and vertebral deformity often used interchangeably. There is also substantial geographical variation in the prevalence of vertebral fracture in men across Europe, with the highest rates in Scandinavian countries. The European Prospective Osteoporosis Study showed an increased incidence of morphometric vertebral fractures with age in both sexes (Figure 2), but the rates were higher in women than men (Roy et al 2003). The only significant determinant of vertebral fracture incidence in men was body mass index (BMI), with reduced risk in those with a high BMI.

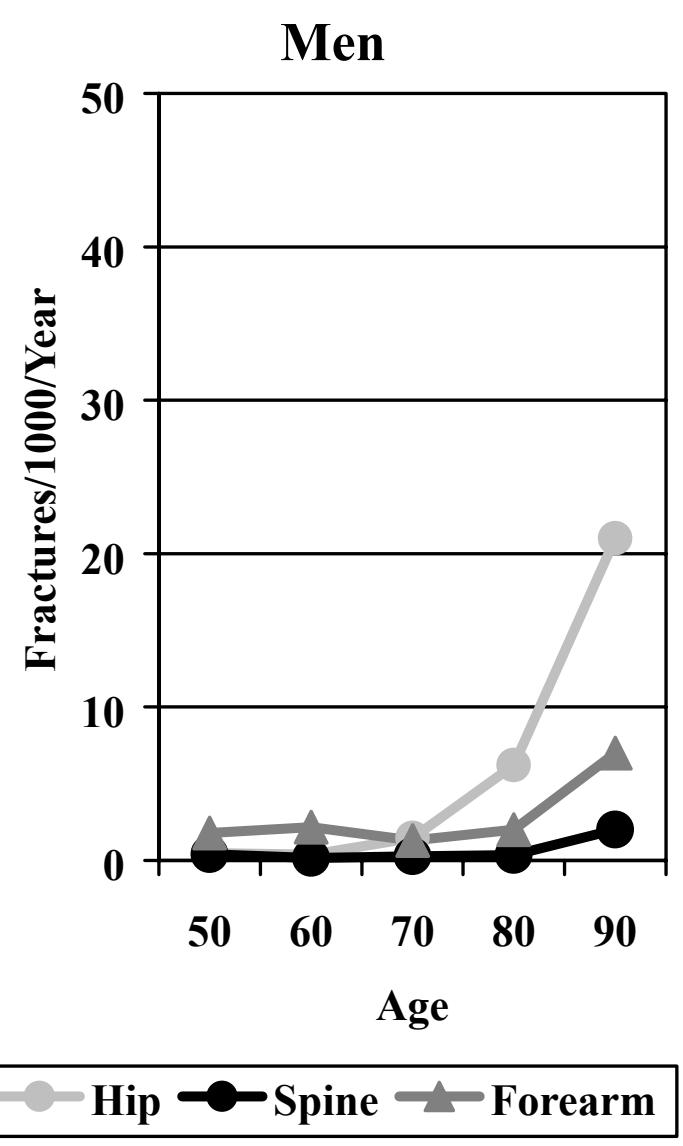

Figure I The incidence of forearm, symptomatic vertebral and hip fractures in men and women from Cardiff (Johansen et al 1997). 


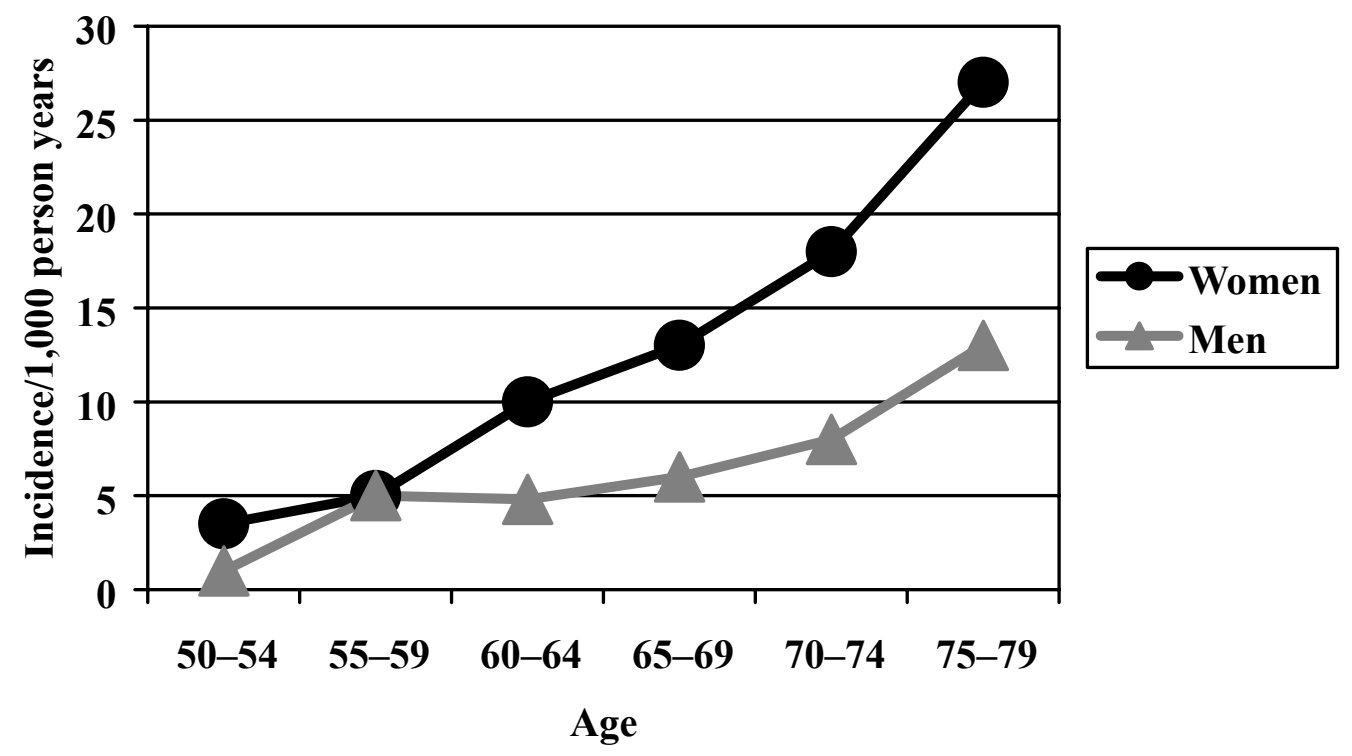

Figure $\mathbf{2}$ The incidence of morphometric vertebral fractures in men and women in the European Prospective Osteoporosis Study (Roy et al 2003).

Hip fractures are the most serious consequence of osteoporosis as they have the most severe impact in terms of morbidity and mortality and result in huge costs for health and social services. In the USA, hip fractures cost $\$ 15$ billion in 1998 and results in 60,000 admissions to nursing homes annually (Seeman 2001). The incidence of hip fractures increases exponentially with age in both sexes in all geographical areas and ethnic groups (Johansen et al 1997; Figure 1). There is a greater difference in hip fracture incidence between ethnic groups and countries than between sexes, highlighting the potential importance of environmental, genetic and lifestyle factors in the etiology of hip fractures. The highest incidence of hip fracture is in Scandinavia, with the lowest rates in Mediterranean countries (Pande and Francis 2001).

Low trauma distal forearm fracture is widely regarded as a typical early manifestation of post-menopausal osteoporosis in women (Eastell 1996; Cuddihy et al 1999). Indeed, 50\% of women who suffer a distal forearm fracture of Colles' type will have osteoporosis (Earnshaw et al 1998). Traditionally, this has not been thought to be the case for men. This is partly because the incidence of these fractures is much lower in men than in women at 9 per 10000 person years as opposed to 36.8 per 10000 person years (O'Neill et al 2001) and does not increase with age in the same way. It has been suggested (Eastell 1996) that this is because men have a higher peak bone mass at this site than women and have no decrease in distal forearm BMD with age. In normal men Butz et al (1994) found a rate of trabecular bone loss of $0.59 \%$ year at the forearm and a similar rate of loss was found by Berntsen et al 2001. The incidence of forearm fracture does rise in the very old (O’Neill et al 2001). Furthermore, low femoral neck bone density has been demonstrated to be a major risk factor for forearm and wrist fractures in men, along with height loss, dietary calcium and history of falls (Nguyen et al 2001). Cuddihy et al 1999 have shown that men have a 2.7 fold and a 10.7 fold increase in hip and vertebral fractures respectively following a distal forearm fracture. Finally, in a case-control study, $41.8 \%$ of men sustaining distal forearm fractures were found to be osteoporotic in at least one site (Tuck et al 2002); this is comparable to that seen in women with distal forearm fractures (Earnshaw et al 1998).

\section{Morbidity and mortality}

There is considerable disability after hip fracture in men, with only $21 \%$ living independently in the community a year later, whereas $26 \%$ receive home care and $53 \%$ live in an institution (Poor et al 1995). Although not all vertebral fractures come to medical attention, symptomatic fractures typically cause acute episodes of back pain, which usually settle after $6-8$ weeks. Men with symptomatic vertebral fractures commonly complain of back pain, loss of height and kyphosis, but also have significantly less energy, poorer sleep, more emotional problems and impaired mobility than age-matched control subjects (Scane et al 1999).

There is an increased mortality after all major fracture in men and women, with much of the excess mortality occurring in the first year. This excess mortality is higher in men than it is in women (Figure 3). The standardized mortality ratio after a hip fracture is 3.17 in men and 2.18 in women and for vertebral fractures this is 2.38 and 1.66 respectively, but 


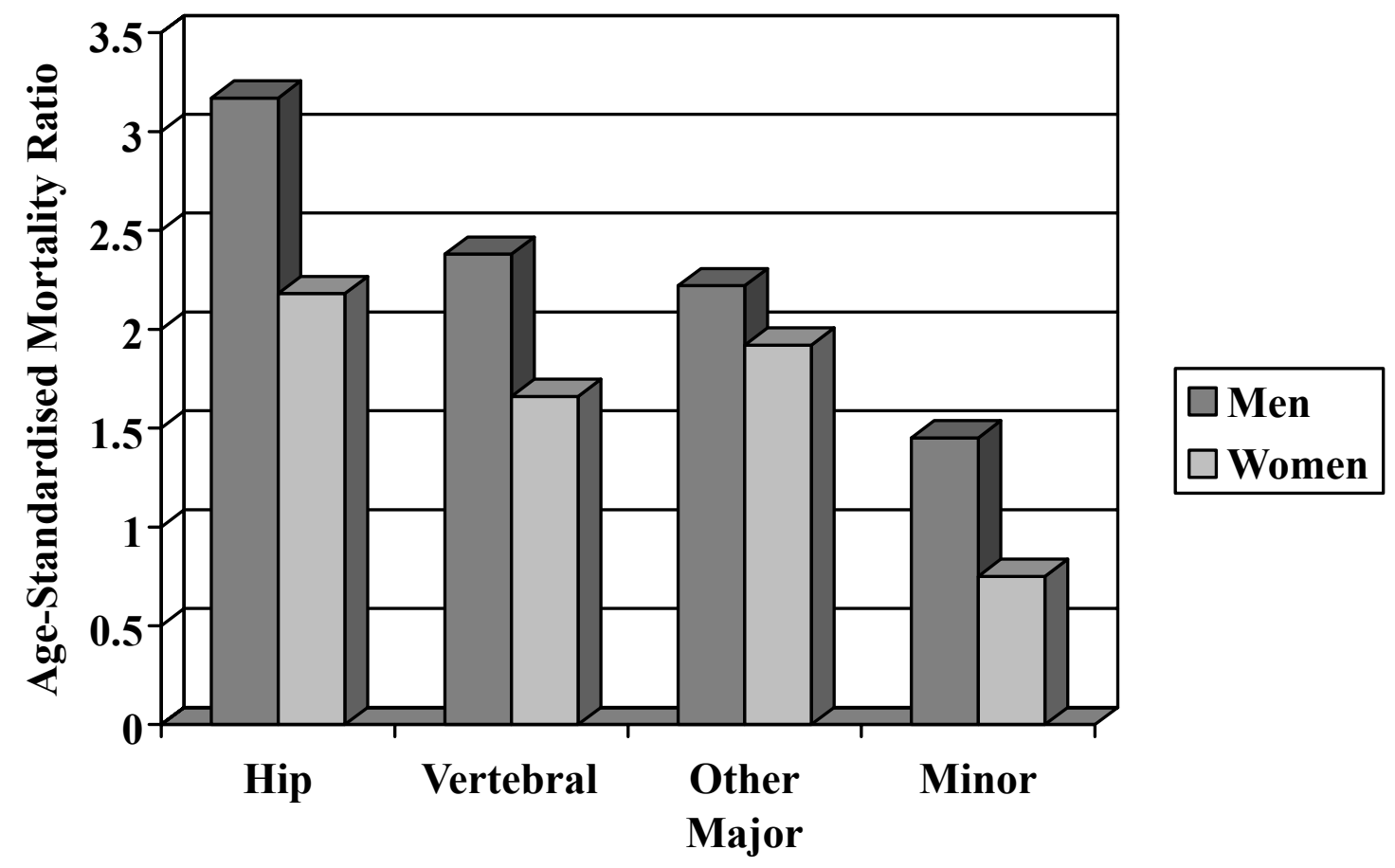

Figure 3 The Age-Standardised Mortality Ratio after fractures in men and women (Center et al 1999).

the reason for the higher mortality in men remains uncertain (Center et al 1999). One possibility is that this may be due to a higher prevalence of co-existing conditions, which are associated with an increased risk of fracture and mortality.

\section{Pathogenesis of low trauma fractures in men}

The risk of fracture is determined by skeletal and non-skeletal risk factors. The skeletal risk factors include BMD, bone turnover, trabecular architecture, bone size, and skeletal geometry, whereas non-skeletal risk factors include postural instability and propensity for falling. There is an inverse relationship between BMD and the incidence of vertebral and hip fractures in men (Figure 4), which is similar to that observed in women (De La et al 1997; Van der Klift et al 2002). Case-control studies show that men with distal forearm, symptomatic vertebral and hip fractures have lower BMD than age-matched control subjects (Scane et al 1999; Pande et al 2000; Tuck et al 2002) (Figure 5); therefore, lower BMD is associated with an increased risk of fracture.

\section{Non-skeletal risk factors (falls)}

A number of studies, mainly in women, show that the risk of fracture is determined not only by BMD and other skeletal factors, but also by non-skeletal factors associated with physical frailty and an increased risk of falls (Cummings et al 1995; Dargent-Molina et al 1996). A prospective study from Australia showed that the combination of low BMD and high body sway conferred a greater risk of fracture than either one alone (Nguyen et al 1993). In the same study, there was also an increased risk of fracture with quadriceps weakness, falls in past year, previous fractures, low body weight and short stature. In men and women the risk of hip fractures is also increased by conditions predisposing to falls, such as strokes, Parkinsonism, dementia, vertigo, alcoholism and visual impairment (Grisso et al 1991; Poor et al 1995).

\section{Secondary causes}

Osteoporosis may be either primary (idiopathic) or secondary to one of a number of identifiable causes. In either case the end result is a low BMD and a propensity for low trauma fractures. The development of osteoporosis may be accelerated by underlying secondary causes of bone loss such as hypogonadism and steroids, which are found in over $50 \%$ of men presenting with symptomatic vertebral crush fractures (Baillie et al 1992). A case-control study from the Mayo Clinic investigated 105 men with vertebral fractures and 105 age-matched control subjects with Paget's disease of bone. This showed a significantly increased relative risk of vertebral fractures with smoking, alcohol consumption 


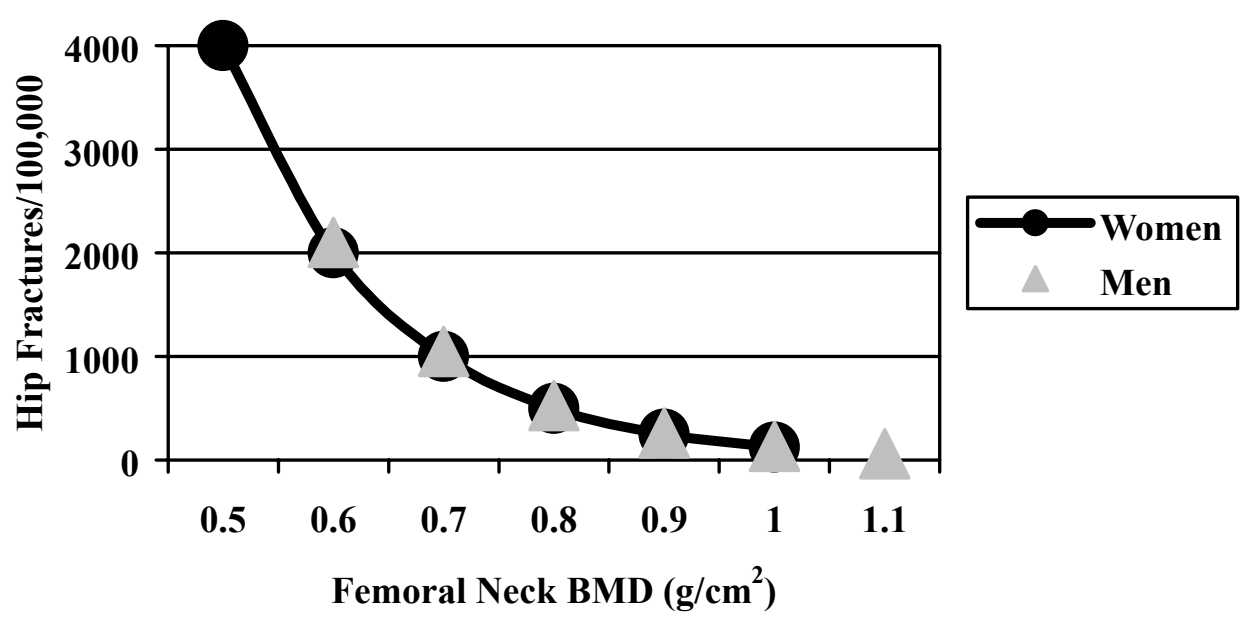

Figure 4 The relationship between femoral neck BMD and the incidence of hip fractures in 80 year old men and women in the Rotterdam Study (De Laet et al 1997).

and underlying secondary causes of osteoporosis, whilst the risk was reduced in the presence of obesity (Seeman et al 1983). A subsequent case-control study from Newcastle has demonstrated an increased risk of vertebral fractures with oral steroid therapy, anticonvulsant treatment, smoking, alcohol intake $>20$ units/week, physical inactivity and low free androgen index (Scane et al 1999). Case-control studies of hip fractures in men have also shown an increased risk of fracture with disorders associated with secondary osteoporosis (Stanley et al 1991). The major secondary causes of osteoporosis in men are given in Table 1.

\section{Diagnosis of male osteoporosis}

The use of bone density measurement

Until the development of DXA the diagnosis of osteoporosis in men was based on the history of fractures after minimal trauma. The introduction of DXA bone density measurement allowed a more objective diagnosis of osteoporosis and stimulated interest in making the diagnosis before fractures occur. The World Health Organization (WHO) has defined osteoporosis as a BMD 2.5 standard deviations or more below the mean value for young adults ( $\mathrm{T}$ score $<-2.5$ ), but this has only been established for women.

Although the reference ranges for BMD measurements in men are derived from a smaller sample size than in women, there is a similar inverse relationship between absolute BMD and the incidence of vertebral and hip fractures in both sexes (De Laet et al 1997; Van der Klift et al 2002). This indicates that the same threshold value of absolute BMD could be used for the diagnosis of osteoporosis in men and women. A T score of -2.5 in women would therefore be equivalent to a $\mathrm{T}$ score of -2.8 in men, calculated

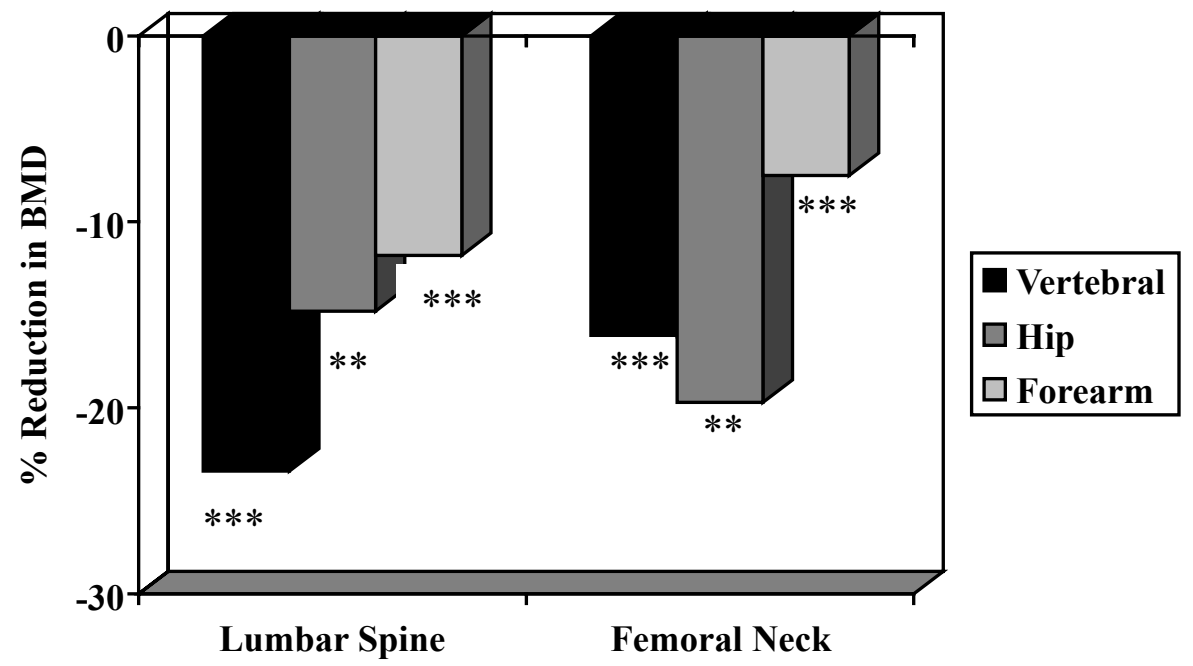

Figure 5 The mean reduction in lumbar spine and femoral neck BMD in men with distal forearm (Tuck and Raj 2002), symptomatic vertebral (Scane et al I999) and hip (Pande et al 2000) fractures compared with age-matched male control subjects. The statistical significance is indicated $(* *=p<0.01$, $* * *=p<0.00 \mathrm{I})$. 
Table I Causes of secondary oeteoporosis in men

\begin{tabular}{lll}
\hline Major causes with & Hypogonadism & \\
strong evidence & Alcoholism & \\
& Corticosteroids & \\
Transplantation & \\
Other causes & Hormonal & - hyperparathyroidism \\
& Gastric surgery & - thyrotoxicosis \\
Gastrointestinal disorders & - celiac disease \\
& & - inflammatory bowel \\
& & disease \\
& Drugs & - liver disease \\
& Idiopathic & - anticonvulsants \\
& hypercalciuria & \\
Malignancy & \\
Chemotherapy & \\
&
\end{tabular}

using gender specific normative data. The prevalence of osteoporosis in men using this diagnostic threshold is too low, whereas the prevalence of $\mathrm{T}$ score $<-2.5$ at the hip, spine or forearm in men over the age of 50 years is broadly comparable to the lifetime risk of fractures at these sites (Melton et al 1998). This suggests that the WHO criteria may be applicable for the diagnosis of osteoporosis in men and women. More recently, De Laet et al (2002) using mathematical models and data from a large prospective study in Rotterdam, concluded that using male specific $\mathrm{T}$ score of -2.5 best fitted the available data. The International Society for Clinical Densitometry Position Development (ISCD) Panel and Scientific Advisory Committee also came to this conclusion in 2002 and is contained in their official positions statement 2005 (Binkley et al 2002). The ISCD's official positions have been endorsed by the American Society for Bone and Mineral Research (ASBMR) and the International Osteoporosis Foundation.

Although only about $50 \%$ of men with apparently low trauma vertebral fractures have densitometric evidence of osteoporosis at the lumbar spine or femoral neck, a further $40 \%$ have osteopenia (Scane et al 1999). It has therefore been suggested that treatment for osteoporosis should be considered in men with low trauma vertebral or hip fractures and evidence of osteoporosis or osteopenia at the lumbar spine or femoral neck, whereas the possibility of unrecognized antecedent trauma should be explored in those with normal bone density measurements (Tuck and Francis 2006).

The fact that only $50 \%$ of men are osteoporotic according to BMD measurements by DXA may be partly due to the uncertainties of threshold values for osteoporosis in men.
It may also reflect that other aspects of size, structure and geometry may be important in determining fracture risk.

\section{Investigation of osteoporosis in men}

Secondary causes of osteoporosis should be sought by careful history, physical examination and appropriate investigation (Table 2). Serum testosterone should be measured in a morning sample, because of the diurnal variation in circulating concentration. A recent hip fracture may alter the hypothalamic-pituitary gonadal axis, as well as increasing the alkaline phosphatase, so investigations for secondary osteoporosis should be performed after the patient has recovered from the fracture and subsequent surgery.

Prostate specific antigen should also be measured in men with vertebral fractures and symptoms of prostatism or evidence of sclerosis on x-rays. In elderly men with osteoporosis, serum 25 hydroxyvitamin D (25OHD) and intact parathyroid hormone (PTH) measurements may be used to exclude vitamin D insufficiency and secondary hyperparathyroidism (Al-oanzi et al 2006).

These investigations are usually normal in men with idiopathic osteoporosis, apart from a transient rise in serum alkaline phosphatase after fracture. The most frequently encountered causes of secondary osteoporosis in men are oral steroid therapy, hypogonadism, alcohol abuse, myeloma and skeletal metastases. In men with severe unexplained osteoporosis, it may be worthwhile considering 24-hour urine calcium estimation to identify hypercalciuria, 24-hour urine cortisol to exclude Cushing's syndrome and anti-endomysial antibodies to look for coeliac disease. Although up to $50 \%$ of male osteoporotics may have no identifiable etiology, elderly males have much higher likelihood of having identifiable secondary cause than younger men. The younger male osteoporotics have been shown to have several and varied possible secondary causes (Varanasi et al 1999).

\section{Management of osteoporosis in men}

The management of osteoporosis should include symptom relief, lifestyle measures to prevent bone loss and decrease the risk of falls and specific treatment to increase BMD and reduce the incidence of fractures. All patients should be offered analgesia of potency appropriate for the severity of their pain. Transcutaneous electrical nerve stimulation (TENS) is also of value in some patients with vertebral fractures. For persistent pain there is now the option of vertebroplasty or kyphoplasty, where this technique is available. Advice from a physiotherapist may help to maintain mobility and prevent falls, as may occupational therapy assessment. 
Table 2 Investigations for secondary osteoporosis in men

\begin{tabular}{lll}
\hline Investigation & Finding & Possible Cause \\
\hline Full blood count & Anemia & Neoplasia or malabsorption \\
ESR & Macrocytosis & Alcohol abuse or malabsorption \\
Biochemical profile & Raised ESR & Neoplasia \\
& Hypercalcemia & Suppressed TSH; high $\mathrm{T}_{4}$ or $\mathrm{T}_{3}$ \\
& Abnormal liver function & Alcohol abuse or liver disease \\
Thyroid function tests & Persistently high AP & Skeletal metastases \\
Serum and urine immunoelectrophoresis & Suppressed TSH; high T or T $_{3}$ & Hyperthyroidism \\
Testosterone, SHBG, LH, FSH & Paraprotein band & Myeloma \\
& Low testosterone or free testosterone & Hypergonadotrophic hypogonadism with \\
& index & raised gonadotrophins \\
Prostate specific antigen & & Hypogonadotrophic hypogonadism with \\
Vitamin D & & low gonadotrophins \\
PTH & Raised levels (often markedly so) & Skeletal metastases from prostate cancer \\
& Low & Osteomalacia \\
Anti-endomysial antibodies & High & Primary or secondary hyperparathy- \\
\hline
\end{tabular}

Advice and support is also available from self-help groups such as the National Osteoporosis Society (http://www.nos. org.uk).

Men with osteoporosis should be given advice on lifestyle measures to decrease bone loss, including a balanced diet rich in calcium, weight bearing exercise, cessation of smoking, moderation of alcohol intake and maintenance of regular exposure to sunlight in summer months. Where there is a history of recurrent falls, falls assessment and multifactorial intervention strategies may decrease the risk of falls. Hip protectors may potentially decrease the risk of hip fractures in frail elderly patients with recurrent falls, although compliance with their use is poor.

\section{Treatment of osteoporosis in men}

Any underlying secondary cause of osteoporosis should be treated if possible, as specific treatment of underlying conditions such as hyperthyroidism, hypogonadism and hyperparathyroidism may increase bone density by $10 \%-20 \%$. There are a number of therapeutic options for idiopathic osteoporosis in men, including bisphosphonates, teriparatide, calcitonin and calcium and vitamin D supplementation. The best data are available for alendronate and teriparatide: Table 3 summarizes the data for the available treatments.

\section{Established treatments}

The established treatments for osteoporosis can be divided, based on underlying molecular physiology, into two broad biological categories: anabolic agents that directly stimulate bone formation and antiresoptive agents that inhibit osteoclast-mediated bone resorption. Both these agents increase BMD and reduce fracture risk. The extent of fracture risk of reduction with antiresoptives is rarely greater than $50 \%$ of the baseline risk (Rosen and Billzekian 2001). The antiresorptives, such as bisphosphonates, calcitonin, testosterone in men and estrogen for women, reduce remodeling and prolong mineralization duration. Anabolic agents, such as parathyroid hormone and strontium, directly stimulate bone formation.

\section{Bisphosphonates}

Bisphosphonates (BPs) are widely used as antiresorptive agents for the treatment of osteoporosis as well as other metabolic bone diseases, including Paget's disease, and tumor-associated bone disease. All BPs are synthetic pyrophosphates an analog, ie, oxygen in P-O-P has been replaced by a carbon, resulting in a P-C-P backbone structure. They have a high affinity for bone mineral and are resistant to chemical and enzymatic hydrolysis. Two additional chains ( $\mathrm{R} 1$ and R2, respectively) have been modified to produce different pharmacological properties and potencies (Table 4). The antiresoptive action of bisphosphonates is thought to result from their ability to bind strongly to bone and suppress osteoclast-mediated bone resorption. At higher doses however most BPs can inhibit normal mineralization and therefore the relative potency of a particular BP is given as a ratio of its antiresoptive activity to its normal mineralization inhibitory action. The relative potency is a function of the chemical structure, especially of the R1 and R 2 chains. The newer compounds have a higher relative potency, as a result of which their relative risk of inhibiting bone mineralization leading to osteomalacia is lower. 
Table 3 Summary of the available evidence for treatments of male osteoporosis $(A=$ randomised controlled trials, $B=$ other well designed studies, $\mathrm{C}=$ expert opinion/reports)

\begin{tabular}{lllll}
\hline Treatment & $\begin{array}{l}\text { Increase in BMD } \\
\text { (spine and/or hip) }\end{array}$ & $\begin{array}{l}\text { Reduction in } \\
\text { vertebral fractures }\end{array}$ & $\begin{array}{l}\text { Reduction in } \\
\text { hip fractures }\end{array}$ & $\begin{array}{l}\text { Reduction in } \\
\text { non-vertebral } \\
\text { fractures }\end{array}$ \\
\hline $\begin{array}{l}\text { Alendronate } \\
\text { Etidronate }\end{array}$ & A & A & None & None \\
Risedronate & B & None & None & None \\
Pamidronate & C & None & None & None \\
lbandronate & C & C & None & None \\
Clodronate & C & None & None \\
Teriparatide & A & A & None & None \\
Calcium and & A & None & None & None \\
vitamin D & A (older men) & None & None \\
Calcitonin & A & None & None & None \\
Strontium & C & None & None & None \\
Androgens & B & None & & \\
\hline
\end{tabular}

BPs have become the treatment of choice for most men with osteoporosis, following the publication of a large, randomized control trial of oral alendronate. This compared the effect of two years' treatment with $10 \mathrm{mg}$ daily alendronate (Fosamax) and placebo in 241 men with osteoporosis aged between 31 and 87 years, 36\% of whom were hypogonadal (Orwoll et al 2002). This showed significant improvement in lumbar spine and femoral neck BMD with alendronate (Figure 6), with similar increases in BMD in eugonadal and hypogonadal men. There was also a significant reduction in vertebral fracture incidence and decrease in height loss with alendronate. Similar results were reported by two other RCTs: one in 134 men with primary osteoporosis and another with 77 men (Gonelli et al 2003). The daily preparation of alendronate has now been licensed in the UK for the treatment of osteopo-

Table 4 Relative potencies of bisphosphonates

\begin{tabular}{|c|c|c|}
\hline Bisphosphonates & Side Chains RI, R2 & Relative Potency \\
\hline Etidronate & $\begin{array}{l}\mathrm{RI}=-\mathrm{OH} \\
\mathrm{R} 2=-\mathrm{CH}_{3}\end{array}$ & 1 \\
\hline Clodronate & $\begin{array}{l}\mathrm{RI}=-\mathrm{Cl} \\
\mathrm{R} 2=-\mathrm{Cl}\end{array}$ & 10 \\
\hline Pamidronate & $\begin{array}{l}\mathrm{RI}=-\mathrm{OH} \\
\mathrm{R} 2=-\mathrm{C}_{2} \mathrm{H}_{4} \mathrm{NH}_{2}\end{array}$ & 100 \\
\hline Alendronate & $\begin{array}{l}\mathrm{RI}=-\mathrm{OH} \\
\mathrm{R} 2=-\mathrm{C}_{3} \mathrm{H}_{6} \mathrm{NH}_{2}\end{array}$ & 500 \\
\hline Risedronate & $\mathrm{RI}=-\mathrm{OH}$ & 1000 \\
\hline Ibandronate & $\begin{array}{l}\mathrm{RI}=-\mathrm{OH} \\
\mathrm{R} 2=-\mathrm{C}_{2} \mathrm{H}_{4} \mathrm{~N}\left(\mathrm{CH}_{3}\right) \mathrm{C}_{5} \mathrm{H}_{1 \mathrm{I}}\end{array}$ & 10000 \\
\hline Zoledronate & $\mathrm{RI}=\mathrm{N}$ & 100000 \\
\hline
\end{tabular}

rosis in men. There is no reason to think that the $70 \mathrm{mg}$ weekly preparation would not be equally effective and many patients find the weekly preparation more convenient.

Observational studies in men with idiopathic and secondary osteoporosis suggest that intermittent cyclical etidronate therapy (Didronel PMO) increases BMD at the lumbar spine by $5 \%-10 \%$, with smaller increases at the hip. In an uncontrolled study in 42 men with vertebral fractures, cyclical etidronate increased spine BMD by $3 \%$ annually, whilst hip bone density showed a non-significant rise of $0.7 \%$ per year (Anderson et al 1997). It would therefore appear that cyclical etidronate has comparable effects on bone density in men and women, although the effect on fracture incidence in men remains unclear.

Although there are no published studies of the effect of risedronate (Actonel) in men with idiopathic osteoporosis, there is no reason to suspect that it would be ineffective, particularly as it has been shown to be beneficial in men and women with glucocorticoid-induced osteoporosis. Furthermore, data from Ringe et al (2004) have demonstrated that there was a significant increase in BMD and a $60 \%$ reduction in new vertebral fractures after 1 year of treatment with risedronate in osteoporotic men, but this has only been published in abstract form. As risedronate has considerable evidence for increasing BMD and reducing fracture rates in women it is probably the second choice bisphosphonate after alendronate.

Further evidence that bisphosphonates are equally effective in men and women is provided by a three year RCT in 677 men and women with osteoporosis and at least one vertebral fracture. There were 84 men randomized to receive clodronate or placebo (McCloskey et al 1999). Interim analysis at one year showed a significant increase in lumbar spine and total 


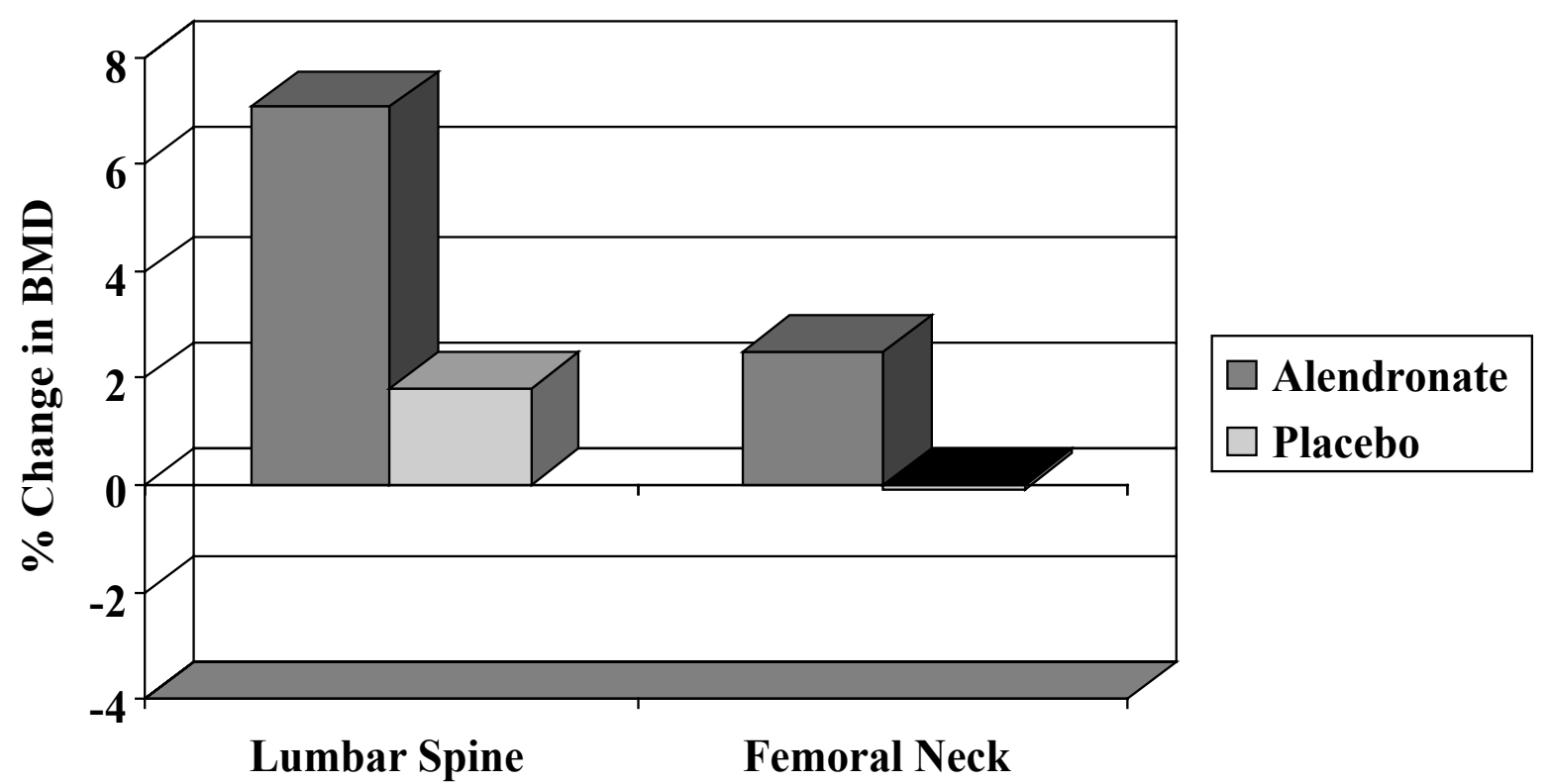

Figure 6 The change in lumbar spine and femoral neck BMD in men with osteoporosis treated with alendronate or placebo (Kurland et al 2000). The statistical significance between the two groups is indicated $(* * *=p<0.001)$.

hip BMD with clodronate compared with placebo, with similar changes in men and women. There was also an overall reduction in vertebral fracture incidence with clodronate.

Intravenous BPs are unlicensed for the treatment of osteoporosis, but are nevertheless widely used in patients unable to tolerate oral BPs. There have been few published studies of intravenous BPs and none solely in men or demonstrating antifracture efficacy. One abstract showed a significant increase in lumbar spine BMD in men 12 months after $30 \mathrm{mg}$ of intravenous pamidronate given at monthly intervals (Tuck and Fordham 2001). Miller et al demonstrated that IV pamidronate (30 mg every three months) produced similar response rates to standard therapy with oral BPs (Miller et al 2005). Adverse events were uncommon and included myalgias and flu-like symptoms. In a small, pilot study of 14 men with idiopathic osteoporosis intravenous ibandronate produced a significant $6.7 \%$ increase in lumbar spine BMD in combination with calcium and vitamin D supplementation (Lamy et al 2003). There were also significant falls in bone turnover markers (beta crosslinks and osteocalcin) of $30 \%-45 \%$. Ibandronate is also available orally as monthly and 3 monthly preparations and increases BMD and reduces fractures in women, but there are no data available in men. Zoledronate is a potent bisphosphonate, which need only given as an infusion annually, but there is no data in men except for those with cancer. The less frequent dosing offered by ibandronate and zoludronate is likely to increase compliance, but anti-fracture evidence is required.
Oral BPs have to be taken during fasting and food must has be avoided for at least thirty minutes after alendronate or risedronate. This is necessary as the gastrointestinal absorption of orally administered BPs is poor, and the absorption can be almost totally abolished by simultaneous ingestion with food, divalent cations and certain medication. Therefore, many of the elderly patients who may also be taking iron or calcium supplements should avoid taking BPs at same time as any of these medications.

Oral BPs also need to be taken either sat upright or standing and are contraindicated in patients with impaired esophageal emptying. This contraindication is to avoid esophageal erosion, which is one of the most serious side effects of oral BPs. This is particularly so for the amino-bisphosphonates and these should be avoided in patients with peptic ulcers and reflux esophagitis. Parental administration can cause acute hypocalcemia, but this is rarely seen in oral therapy. However, alendronate and risderonate may cause mild hypocalcemia and hypophosphatemia, and increase PTH and worsen hyperparathyroidism. There have been reports of non-specific renal damage by BPs, but that is only seen with high doses. BPs should therefore be used cautiously in patients with renal insufficiency.

\section{Teriparatide}

Teriparatide is a recombinant fragment of human parathyroid hormone (PTH) composed of 1-34 amino acids and has anabolic properties, which make it useful for treating 
osteoporosis in men. PTH stimulates both bone formation and resorption, leading to increased or decreased BMD, depending on the mode of administration. Continuous infusion causes persistent elevation of PTH and results in greater resorption than formation, leading to bone loss. In contrast, daily injections of PTH lead to only transient peaks in serum PTH, resulting in greater bone formation and an increase in BMD.

In postmenopausal women with prior vertebral fractures, teriparatide increases BMD and reduces both vertebral and non-vertebral fractures (Neer et al 2001). In a small study of subcutaneous rhPTH (1-34) 400 IU daily in 23 men aged $30-68$ years, BMD increased by $13.5 \%$ in the lumbar spine and by $2.9 \%$ at the femoral neck over 18 months (Kurland et al 2000). Another study in 437 osteoporotic men, showed significant increases in lumbar spine and femoral neck after a median of 11 months' treatment with subcutaneous teriparatide 20 and $40 \mu \mathrm{g}$ daily (Orwoll et al 2003: Figure 7). Kaufman et al 2005 continued to observe 355 of these men over a period of 30 months and found that BMD gradually fell after cessation of teriparatide, but remained significantly higher than that at baseline. The rate of new vertebral fracture was also significantly reduced by $51 \%$. Given the fall in BMD after stopping teriparatide, the question remained as to whether BPs would increase the BMD if given in combination or stop the fall if given after teriparatide. Kaufman et al in their observational study found that those men given BPs after teriparatide maintained their BMD and tended towards further increases. Kurland et al (2004) reported an obser- vational study of 21 men and also reported that there were significant increases in lumbar spine BMD if BPs were given after cessation of teriparatide. Recently, a trial was reported in which 83 men were randomized to receive alendronate or teriparatide alone or in combination. Those given teriparatide alone had significantly greater BMD than either of the other two groups (Finkelstein et al 2003) It therefore appears that BPs should be given after teriparatide to maintain the BMD, but not used in combination as they attenuate the effects of teriparatide. Side effects of teriparatide include nausea, headache and transient mild hypercalcaemia, but these were reported less commonly with the $20 \mu \mathrm{g}$ dose. Teriparatide has therefore been licensed for use at a recommended dose of $20 \mu \mathrm{g}$ daily for an 18 month course of treatment.

In Europe, teriparatide is licensed for a treatment course of 18 months and in the USA for 24 months. Teriparatide is contraindicated in patients with Paget's disease of bone and unexplained elevation of alkaline phosphatase, as they are considered to be at an increased baseline risk for osteosarcoma. It should not be used in patients with metabolic bone disease other than osteoporosis, such as hypercalcemia or metastatic bone metastases. The British Society for Rheumatology also recommends caution in ankylosing spondylitis, diffuse idiopathic skeletal hyperostosis (DISH), lumbar canal stenosis, urolithiasis and gout.

Administration of $20 \mu \mathrm{g}$ dose of teriparatide leads to transient hypercalcemia, which is seen approximately 2 hours after the dose and reached maximum between 4 to 6 hours. Neer et al observed mild hypercalcemia, defined as total
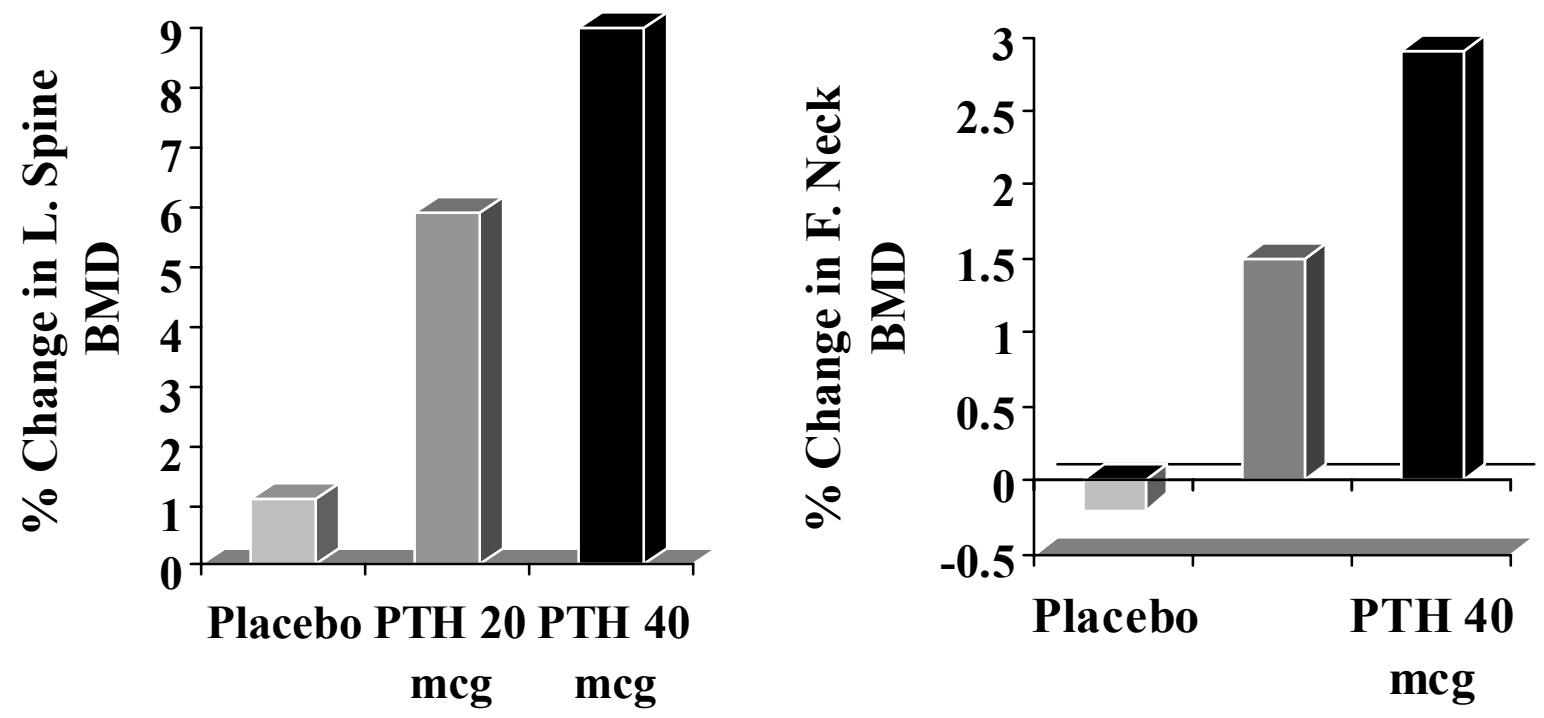

Figure 7 The change in lumbar spine and femoral neck BMD on treatment with subcutaneous Teriparatide $20 \mu \mathrm{g}$ and $40 \mu \mathrm{g}$ daily or placebo injections in men with osteoporosis. The statistical significance of differences from the placebo group is indicated (Kurland et al 2000:* $=p<0.05$, *** $=p<0.001$ ). 
calcium of $>10.6 \mathrm{mg} / \mathrm{dL}$, in $11 \%$ of women receiving 20 $\mu \mathrm{g}$ dose of teriparatide (Neer et al 2001). Transient episodes of orthostatic postural hypotension are one of the infrequent adverse effects of teriparatide. This typically occurred in the first several doses and within 4 hours of the dose being administered. The transient orthostatic hypotension resolved within a few minutes to a few hours and did not preclude use of the treatment. Other adverse side effects associated with teriparatide administration include nausea, headache, angina pectoris, constipation, depression, dizziness, insomnia, hypertension, and syncope. There is insufficient data to assess the safety of teriparatide in patients with compromised cardiac, hepatic or renal function.

\section{Calcium and vitamin D}

The role of calcium and vitamin D supplementation in the management of osteoporosis in men remains unclear. In an RCT in 86 normal men aged 30-87, supplementation with $1,000 \mathrm{mg}$ calcium and $1,000 \mathrm{IU}$ of vitamin D daily had no effect of bone loss from the forearm or spine (Orwoll et al 1990). In contrast, an American RCT in 389 older men and women (mean age 70 years) living at home demonstrated that $700 \mathrm{IU}$ vitamin $\mathrm{D}_{3}$ and $500 \mathrm{mg}$ elemental calcium daily had a modest beneficial effect on bone density and decreased the incidence of non-vertebral fractures (Dawson-Hughes et al 1997). Sub-group analysis of the results for the men in this study showed a significant improvement in BMD with calcium and vitamin $\mathrm{D}$, but no reduction in fractures was demonstrated. A recent study of oral vitamin $\mathrm{D}_{3} 100,000 \mathrm{IU}$ every 4 months in 2,037 men and 649 women, aged between 65 and 85 years living in the community, showed an overall $22 \%$ reduction in fracture risk (Trivedi et al 2003). There was no significant reduction in fractures at any specific site or in either gender alone. In the absence of more conclusive studies, it seems reasonable to recommend calcium and vitamin D in frail elderly men, who are likely to have vitamin D deficiency and secondary hyperparathyroidism. Calcium and vitamin D may also be used as an adjunct to other treatments in men with established osteoporosis. It is important to ensure adequate calcium and vitamin D intake before commencing antiresorptive or anabolic treatment for osteoporosis, this is essential to derive optimum benefit and to prevent and mitigate some of the possible adverse side effects of the therapies.

\section{Calcitonin}

Calcitonin, a 32 amino acid peptide, is the most powerful physiological inhibitor of the osteoclast activity. It also inhibits tubular reabsorption of calcium and phosphate, leading to increased rates of their loss in urine. These functions in regulating calcium and phosphate metabolism make it a potentially useful treatment for osteoporosis. Intranasal salmon calcitonin formulations miacalcin and fortical were approved by the FDA in 1995 and in 2005 respectively and there is some data for its use in men.

A small study in 28 men with osteoporosis showed that nasal calcitonin 200 units daily for 12 months increased lumbar spine BMD by $4.7 \%$ compared with control subjects (Figure 8), but resulted in no significant change in BMD at the proximal femur (Trovas et al 2002). A larger randomized control trial has subsequently been performed with 71 men suffering idiopathic osteoporosis, which demonstrated significant increases in both lumbar spine and femoral neck BMD of $3.5 \%$ and $3.2 \%$ respectively compared with

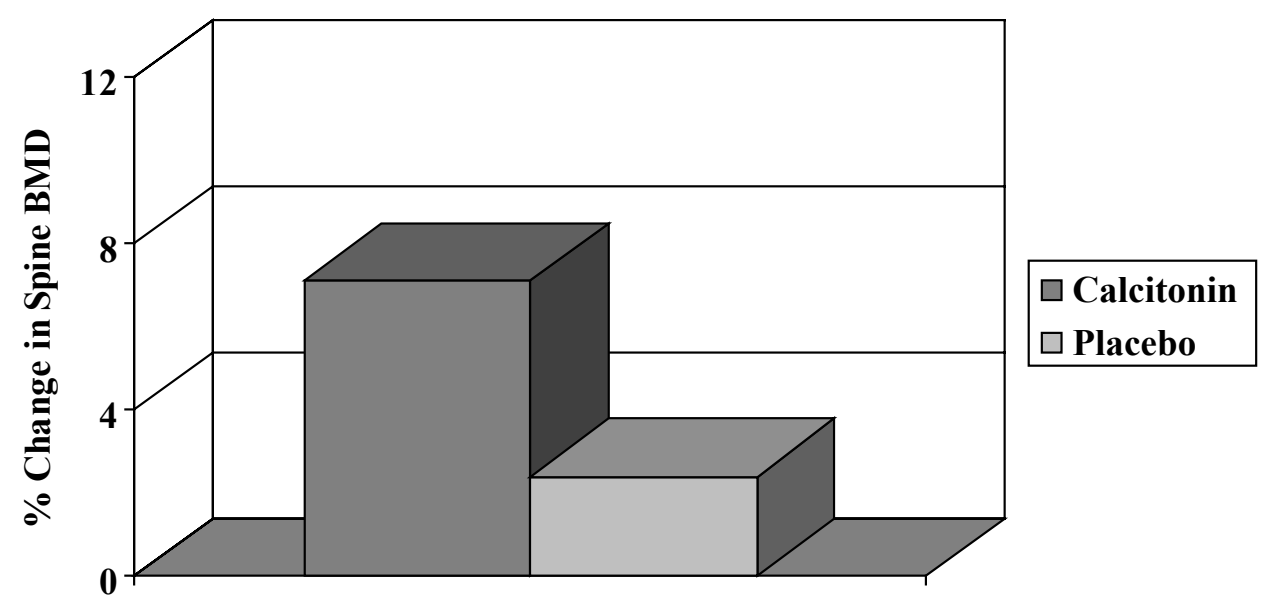

Figure 8 The change in lumbar spine BMD in men with osteoporosis treated with calcitonin or placebo (De Laet et al 1997). The statistical significance between the two groups is indicated. 
controls (Toth et al 2005). There is, however, no anti-fracture evidence as yet in men. Calcitonin may also be useful in the management of the patient with acute vertebral fracture. An RCT in 32 men and 68 women with acute vertebral fracture showed that intranasal calcitonin 200 iu daily for 28 days was more effective than placebo at decreasing pain and improving mobility (Lyritis et al 1997). The common adverse drug reactions associated with injectable calcitonin include nausea and flushing, but these occur less frequently in patients treated with nasal spray.

\section{Alternative agents}

\section{Strontium}

Strontium ranelate is now an established treatment for postmenopausal osteoporosis. It is a novel agent and a new class of drug having a dual action. It both stimulates bone formation and suppresses bone resorption. It increases BMD at the lumbar spine and hip by 14.4 and $8.3 \%$ respectively after three years, although at least half of this increase is the result of the incorporation of metal into bone rather than its effect on bone mineralization (Meunier et al 2004). It also reduces rates of vertebral and non-vertebral fractures, as well as hip fracture in those at high risk (Meunier et al 2004; Reginster et al 2005). However, there is no data available for men. Nevertheless, there is no reason to think that it would not work in men and may therefore be worth consideration when BPs fail.

Strontium ranelate is associated with mild adverse effects, such as transient nausea, diarrhea and creatine kinase elevations. There is an increased incidence of deep vein thrombosis and pulmonary embolism associated with strontium administration and it should so be used with caution in patients at increased risk of venous thromboembolism.

\section{Androgens}

In addition to improving bone density in men with hypogonadal osteoporosis (Behre et al 1999), testosterone may increase spine bone density in eugonadal men with vertebral fractures and there have been a number of small studies. An uncontrolled study of testosterone treatment in 21 eugonadal men with vertebral osteoporosis showed a significant increase in spine bone density of 5\% in six months, but no change in hip bone density was seen (Anderson et al 1997). During treatment there was a $48 \%$ increase in serum testosterone, and a $22 \%$ reduction in $\mathrm{SHBG}$, leading to an $88 \%$ increase in free androgen index. Serum estradiol also increased by $41 \%$. The biochemical markers of bone turnover showed a reduction in bone formation and resorption. Analysis of the changes in bone density and sex steroid concentrations showed a closer relationship between the changes in BMD and serum estradiol than with serum testosterone.

Another small, randomized control trial in 86 osteopoprotic men examined the effects of oral dehydroepiandrosterone (DHEAS) over a 6 month period. As expected there were significantly higher concentrations of DHEAS and IGF-1 (insulin-like growth factor one) in the treatment group. However, DHEAS had only modest effects on BMD of between 2.32 and $3.1 \%$. There were no significant changes in free testosterone, estradiol or PSA (Sun et al 2002). A randomized controlled crossover study in 15 men on long-term glucocorticoid treatment showed an increase in spine bone density of 5\% after 12 months treatment with testosterone, whilst no change was observed during the control period of 12 months observation (Reid et al 1996). Side effect and cardiovascular risk factor profiles were acceptable in these small studies, but androgen treatment needs to be more fully explored in a multicentre randomized controlled trial. Until the results of such studies are available this treatment should also be regarded as experimental.

\section{Calcitriol}

Calcitriol, also known as 1,25 dihydroxyvitamin D, is the hormonally active metabolite of vitamin D. Calcitriol promotes calcium absorption from the bowel and may stimulate osteoblastic new bone formation. In a small RCT in 41 men with idiopathic osteoporosis, there was no difference in the change in spine or femoral neck BMD between those treated with calcitriol and the control group taking calcium supplements (Ebeling et al 2001).

\section{Fluoride salts}

Fluoride salt therapy, mainly as sodium fluoride, has been used for over thirty years to treat osteoporosis. Fluoride is believed to reduce risk of fracture by increasing bone mass and by reducing bone loss. Although fluoride has an ability to increase BMD at lumbar spine, it does not result in a reduction of vertebral fractures. In increasing the dose of fluoride, one increases the risk of non-vertebral fracture and gastrointestinal side effects without any effect on the vertebral fracture rate. (Haguenauer et al 2000) Some clinical trials of fluoride have included men, but it is difficult to ascertain whether responses were in any way gender-specific. A German RCT shows that low dose intermittent monofluorophosphate and calcium increases bone density and decreases the risk of vertebral fractures in men with osteoporosis (Ringe et al 1998). On current evidence fluoride salts cannot be recommended for the treatment of osteoporosis. 


\section{Emerging novel therapies}

Recent advances in the understanding of the functioning and regulation of osteoblast and osteoclast activity has led to the development of a number of novel therapies for the treatment of osteoporosis.

\section{RANKL modulator}

Receptor activator of nuclear factor NF- $\kappa \beta$ ligand (RANKL) is essential for osteoclast differentiation and activity. It acts by binding to RANK expressed on osteoclast precursors stimulating their differentiation into mature osteoclasts. The human monoclonal antibody denosumab, previously known as AMG 162, specifically binds and inhibits RANKL activity. Denosumab mimics osteoprotegerin, which is a soluble RANKL decoy receptor that binds RANKL. Osteoprotegrin is the key endogenous regulator of the RANKL-RANK pathway. Preliminary evaluation, over a period of 12 months in 412 postmenopausal women with low bone mineral density, suggests that denosumab might be an effective treatment for osteoporosis (McLung et al 2006). However, further studies are needed to determine its efficacy as well as any potential side effects (Schwartzmann et al 2006).

\section{Intact human recombinant PTH (I-84)}

Intact human recombinant PTH (1-84) is also under evaluation as an anabolic therapy for the treatment of osteoporosis. The anabolic effect on BMD and fracture reduction, as well as adverse effects of the full-length PTH and of the truncated 1-34 N-terminal form (teriparatide) appears to be comparable (Hodsman et al 2003). Further studies are needed to confirm this observation and to assess the relative efficacy of the two formulations in both women and men.

\section{SERMs}

SERMs (Selective Estrogen Receptor Modulators) are non-hormonal agents that modulate the estrogen receptors in some specific tissues. SERMs can have agonist or anatagonist action, ie, mimicking or inhibiting estrogen respectively. This will vary from tissue to tissue and the design of the agent. For example, raloxifene inhibits estrogen receptors in breast and reduce the risk of breast cancer, but stimulate estrogen receptors in bone improving BMD. Raloxifene has been approved for the prevention and treatment of postmenopausal osteoporosis (Ettinger et al 1999). Pathophysiological considerations suggest that it may also be effective in particular cases of male osteoporosis. However, large scale clinical trials are required to assess their use in men.

\section{Anabolic steroids}

Although agents such as nandrolone decanoate increase bone density transiently in men with osteoporosis, the benefit may be lost in the longer term, possibly because of suppression of the pituitary-gonadal axis, with consequent reduction in endogenous sex hormone production (Hamdy et al 1998). Such treatment may also lead to abnormalities in liver function. Anabolic steroids should therefore be regarded as an experimental treatment.

\section{Other developmental therapies}

There are a number of other compounds in the development stage that have either been designed or isolated. These modulate specific molecules that play critical roles in bone remodeling; the targets include c-src, cathepsin $\mathrm{K}$ and $\alpha_{2} \beta_{3}$ integrin receptor. The efficacy of statins, thiazide diuretics, nitric oxide donors and isoflavones is still being debated and has yet to be established.

\section{Monitoring of treatment}

Once a commitment to treat a patient has been undertaken it is important to assess response to treatment. Treatment failure is said to have taken place when there are further fragility fractures despite adherence to treatment for one year and/or BMD declines below pre-treatment baseline (NICE document 87). Approximately $10 \%-15 \%$ of patients fail to respond to treatment (NOS 1998). Therefore, at least one repeat DXA scan is usually recommended to confirm treatment response. Unfortunately, this has to be done after a minimum of two years of treatment, as it takes this long for response to anti-resorptive agents to exceed the least significant change in BMD. Over a period of 2-3 years the BMD can be expected to increase approximately $5 \%-7 \%$ at the lumbar spine with bisphosphonate therapy. Taking into account this change, the precision of $1 \%-2 \%$ for a typical DXA scanner (Blake and Fogelman 2005) and the coefficient of variation means that the least significant change that can be detected is somewhere between $4.4 \%$ and $6.9 \%$ depending on the site (Cummings et al 2000). Therefore, it will take at least 2 years for a sufficiently large change to have taken place to be sure that the result is a true representation of treatment response. Furthermore, the BMD may fall in the first year of treatment only to subsequently gain in the second year: a phenomenon known as regression to the mean (Eastell and Bainbridge 2001).

The use of BMD has the disadvantages of taking two years before a lack of response will be noted and also the spine can be affected by degenerative changes, especially 
in patients over 65. An alternative is to use bone turnover markers, which have a maximum suppression in the order of $50 \%$ within three months of starting therapy (Eastell and Bainbridge 2001). This would allow earlier identification of non-responders, but they can be difficult to collect, tend to be very variable and are influenced by many factors. For example a recent fracture will cause them to increase and they vary with meals and the time of day. It is therefore important to collect them at the same time of day. Nevertheless, they have been shown to predict further fracture and BMD response. The development of more reliable serum markers has made their use easier. They are increasingly being used to assess early response to treatment and compliance by measuring at baseline and 3-6 months after initiation of treatment.

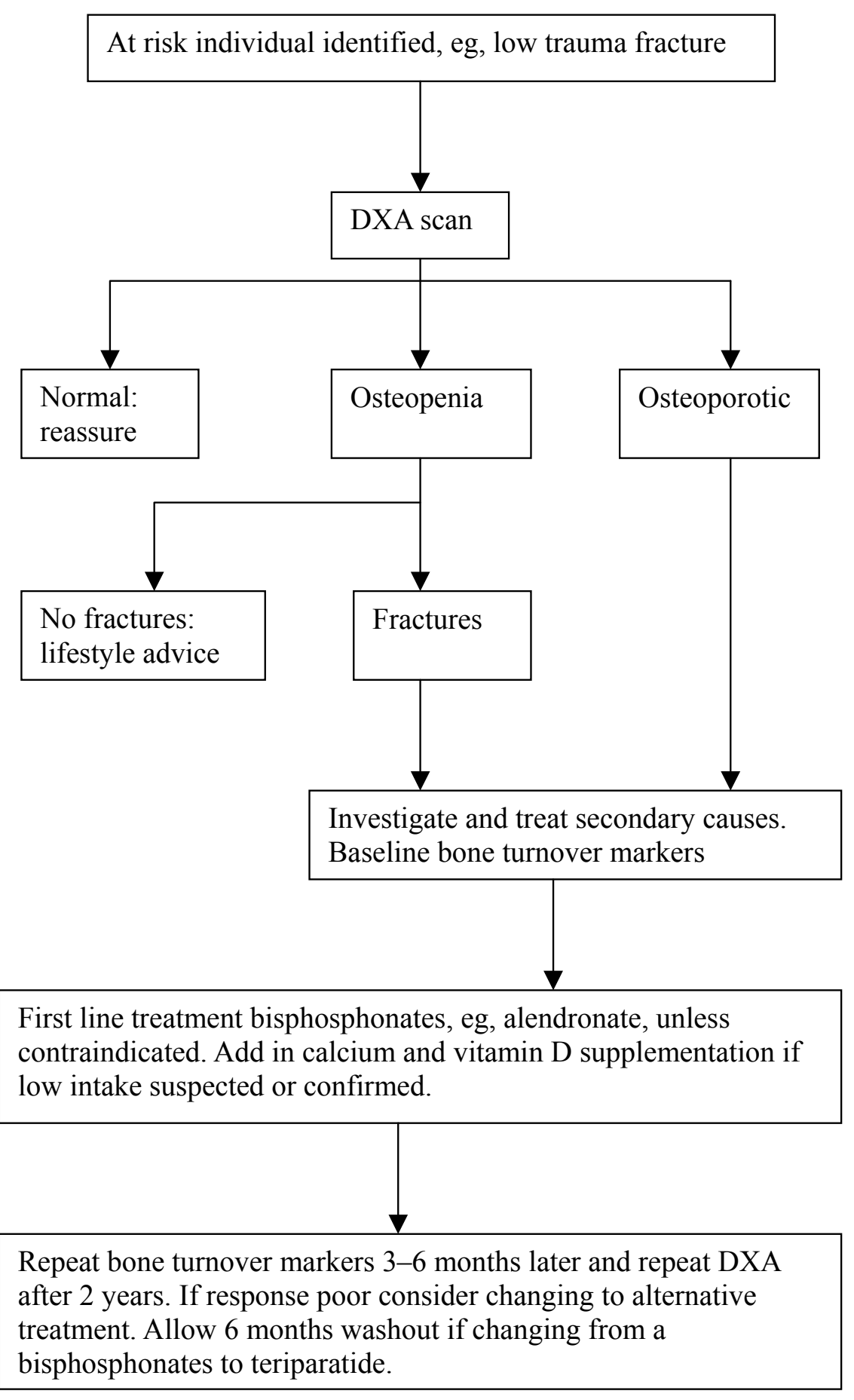

Figure 9 Proposed flow chart for the treatment of men with osteoporosis. 


\section{Conclusion}

Osteoporotic fractures are a major public health problem in men and further work is required to clarify the pathogenesis of the condition. Despite the plethora of new and effective treatments for women there is very little evidence for their use in men. Studies are urgently required to address this issue. A possible treatment strategy using the currently available evidence is shown: Figure 9. The at risk individual, once identified, should have a baseline DXA and investigations for secondary causes undertaken including bone turnover markers. Underlying secondary causes of osteoporosis should be treated where possible, whereas BPs are probably the treatment of choice in other men with osteoporosis. If these are contra-indicated or ineffective, teriparatide or alternatives such as strontium should be considered. Calcium and vitamin D supplements may be useful in frail, elderly men with osteoporosis, who are likely to have vitamin D deficiency and secondary hyperparathyroidism. In the case of BPs, repeating the bone turnover markers 3 to 6 months later could then be used to assess response to therapy and compliance. A DXA scan should be repeated 2 years later. It is hoped that further research will see more treatments licensed for use in men and new agents become available.

\section{References}

Al-oanzi Z, Tuck SP, Raj N, et al. 2006. Assessment of Vitamin D Status in Male Osteoporosis. Clin Chem, 52:248-54.

Anderson FH, Francis RM, Bishop JC, et al. 1997. Effect of intermittent cyclical disodium etidronate therapy on bone mineral density in men with vertebral fractures. Age Ageing, 26:359-65.

Anderson FH, Francis RM, Peaston RT, et al. 1997. Androgen supplementation in eugonadal men with osteoporosis - effects of six months' treatment on markers of bone formation and resorption. J Bone Miner Res, 12:472-78.

Baillie SP, Davison CE, Johnson FJ, et al. 1992. Pathogenesis of vertebral crush fractures in men. Age and Ageing, 21:139-41.

Behre HM, von Eckardstein S, Kliesch S, et al. 1999. Long-term substitution therapy of hypogonadal men with trans-scrotal testosterone over 7-10 years. Clin Endocrinol, 50:629-35.

Binkley NC, Schmeer P, Wasnich RD, et al. 2002. What are the criteria by which densitometric diagnosis of osteoporosis can be made in males and non-caucasians? J Clin Densitomet, 5(Suppl):519-27.

Cuddihy MT, Gabriel SE, Crowson CS, et al. 1999. Forearm fractures as predictors of subsequent osteoporotic fracture. Osteoporosis Int, 9:469-75.

Earnshaw SA, Caute SA, Worley A, et al. 1998. Colles' fracture of the wrist as an indicator of underlying osteoporosis in post-menopausal women. A prospective study of bone mineral density and bone turnover rate. Osteoporosis Int, 8:53-60.

Berntsen GK, Fonnebo V, Sogaard AJ, et al. 2001. Forearm bone mineral density by age in 7,620 men and women: the Tromso study, a population based study. Am J Epidem, 53:465-73.

Blake G, Fogelman I. The radiological diagnosis of osteoporosis. 2005. In Arden N, ed. Osteoporosis Illustrated, $2^{\text {nd }}$ ed. London: Remedica. p 89-116.

Boyce WJ, Vessey MP. 1985. Rising incidence of fracture of the proximal femur. Lancet, I (8421):150-1.

Butz S, Wuster C, Scheidt-Nave C, et al. 1994. Forearm bone mineral density as measured by peripheral quantitative computed tomography (pQCT) in a German reference population. Osteoporosis Int, 4:179-84.
Center JR, Nguyen TV, Schnieder D, et al. 1999. Mortality after all major types of osteoporotic fracture in men and women: an observational study. Lancet, 353:878-82.

Cummings SR, Nevitt MC, Browner WS, et al. 1995. For The Study of Osteoporotic Fractures Research Group. Risk factors for hip fracture in white women. N Eng J Med, 332:767-73.

Cummings SR, Palermo L, Browner W, et al. 2000. Monitoring osteoporosis therapy with bone densitometry: misleading changes and regression to the mean. Fracture Intervention Trial Research Group. JAMA, 283:1318-21.

Dargent-Molina P, Favier F, Grandjean H, et al. 1996. Fall-related factors and risk of hip fracture: the EPIDOS prospective study. Lancet, 348:145-9.

Dawson-Hughes B, Harris SS, Krall EA, et al. 1997. Effect of calcium and vitamin $\mathrm{D}$ supplementation on bone density in men and women 65 years of age and older. N Engl J Med, 337:670-6.

De Laet CE, Van Hout BA, Burger H, et al. 1997. Bone density and risk of hip fracture in men and women: cross-sectional analysis. $B M J$, 315:221-5.

De Laet CE, Van der Klift M, Hofman A, et al. 2002. Osteoporosis in men and women: a story about bone mineral density thresholds and hip fracture risk. J Bone Min Res, 17:2231-6.

Eastell R. 1996. Forearm fracture. Bone, 18(Suppl 3):2035-75.

Eastell R, Bainbridge PR. 2001. Bone turnover markers for monitoring antiresorptive therapy. Osteoporosis Rev, 9:1-5.

Eastell R, Boyle IT, Compston J, et al. 1998. Management of male osteoporosis: Report of the UK Consensus Group. Quart J Med, 91:71-92.

Ensrud KE, Nevitt MC, Palermo L, et al. 1999. What proportion of incident morphometric vertebral fractures are clinically diagnosed and vice versa? J Bone Min Res, 14 (S1):S138.

Ebeling PR, Wark JD, Yeung S, et al. 2001. Effects of calcitriol or calcium on bone mineral density, bone turnover and fractures in men with primary osteoporosis: a two year randomised, double blind, double placebo study. J Clin Endocrinol Metab, 86:4098-103.

Ettinger B, Black DM, Mitlak BH, et al. 1999. Reduction of vertebral fracture risk in postmenopausal women with osteoporosis treated with raloxifene: results from a 3-year randomized clinical trial. Multiple Outcomes of Raloxifene Evaluation (MORE) Investigators. JAMA, 282:637-45.

Feldstein AC, Nichols G, Orwoll E, et al. 2005. The near absence of osteoporosis treatment in older men with fractures. Osteoporosis Int, 16:953-62.

Finkelstein JS, Hayes A, Hunzelman JL, et al. 2003. The effects of parathyroid hormone, alendronate, or both in men with osteoporosis. $N$ Engl J Med, 349:1216-26.

Gonnelli S, Cepollaro C, Montagnani A, et al. 2003. Alendronate treatment in men with primary osteoporosis: a three year longitudinal study. Calcif Tissue Int, 73:133-9.

Grisso JA, Kelsey JL, Strom BL, et al. 1991. Risk factors for falls as a cause of hip fracture in women. The Northeast Hip Fracture Study Group. N Engl J Med, 324:1326-31.

Hamdy RC, Moore SW, Whalen KE, et al. 1998. Nandrolone decanoate for men with osteoporosis. Am J Therapeutics, 5:89-95.

Hodsman AB, Hanley DA, Ettinger MP, et al. 2003. Efficacy and safety of human parathyroid hormone-(1-84) in increasing bone mineral density in postmenopausal osteoporosis. J Clin Endocrinol Metab, $88: 5212-20$

Haguenauer D, Robinson VA, Shea BJ, et al. 2000. Fluoride for treating postmenopausal osteoporosis. The Cochrane Database of Systematic Reviews, Issue 4. Art No: CD002825.

Johansen A, Evans RJ, Stone MD, et al. 1997. Fracture incidence in England and Wales: A study based on the population of Cardiff. Injury, 28:655-60.

Kaufman JM, Orwoll E, Goemaere S, et al. 2005. Teriparatide effects on vertebral fractures and bone mineral density in men with osteoporosis: treatment and discontinuation of therapy. Osteoporosis Int, 16:510-16.

Kiebzak GM, Beinart GA, Perser K, et al. 2002. Undertreatment of osteoporosis in men with hip fracture. Arch Intern Med, 162:2217-22. 
Kurland ES, Cosman F, McMahon DJ, et al. 2000. Parathyroid hormone as a therapy for idiopathic osteoporosis in men: effects on bone mineral density and bone markers. J Clin Endocrinol Metabol, 85:3069-76.

Kurland ES, Heller SL, Diamond B, et al. 2004. The importance of bispohosphonate therapy in maintaining bone mass in men after therapy with teriparatide [human parathyroid hormone (1-34)]. Osteoporosis Int, 15:992-7.

Lamy O, Sandini L, Pache I, et al. 2003. Intravenous ibandronate in men with osteoporosis: an open pilot study over 2 years. J Endocrinol Invest, 26:728-32.

Lyritis GP, Paspati I, Karachalios T, et al. 1997. Pain relief from nasal salmon calcitonin in osteoporotic vertebral crush fractures. A double blind, placebo-controlled clinical study. Acta Orthop Scand, 275 Suppl:112-14

McCloskey E, Selby P, Davies M, et al. 1999. Clodronate decreases vertebral fracture incidence in men and women with established osteoporosis. Calcif Tissue Int, 64(Suppl 1):S82.

McLung MR, Lewiecki EM, Chen SB, et al. 2006. Denosumab in postmenopausal women with low bone mineral density. $N$ Engl $J$ Med, 354:821-31.

Melton LJ., Atkinson EJ, O'Connor MK, et al. 1998. Bone density and fracture risk in men. $J$ Bone Min Res, 13:1915-23.

Meunier PJ, Roux C, Seeman E, et al. 2004. The effects of strontium ranelate on the risk of vertebral fracture in women with postmenopausal osteoporosis. $N$ Engl J Med, 350:459-68.

Miller RG, Chretien KC, Meoni LA, et al. 2005. Comparison of intravenous pamidronate to standard therapy for osteoporosis: use in patients unable to take oral bisphosphonates. $J$ Clin Rheumatol, 11:2-7.

National Institute for Clinical Excellence (NICE) technology apparaisal document number 87: Osteoporosis - secondary prevention 2006.

National Osteoporosis Society (NOS). 1998. Fundamentals of bone densitometry - report of a working party. Bath: National Osteoporosis Society.

Neer RM, Arnaud CD, Zanchetta JR, et al. 2001. Effect of parathyroid hormone (1-34) on fractures and bone mineral density in postmenopausal women with osteoporosis. $N$ Eng J Med, 344:1434-41.

NIH Consensus Development Panel on Osteoporosis Prevention, Diagnosis and Therapy. 2001. Osteoporosis prevention, diagnosis, and therapy. JAMA, 285:785-95.

Nguyen TV, Sambrook P, Kelly P, et al. 1993. Prediction of osteoporotic fractures by postural instability and bone density. BMJ, 307:1111-15.

Nguyen TV, Center JR, Sambrook PN, et al. 2001. Risk factors for proximal humerus, forearm and wrist fractures in elderly men and women: the Dubbo Osteoporosis Epidemiology Study. Am J Epidemiol, 153:587-95.

Obrant KJ, Benger U, Johnell O, et al. 1989. Increasing age-adjusted risk of fragility fractures: a sign of increasing osteoporosis in successive generations? Calcif Tissue Int, 44:57-67.

O'Neill TW, Cooper C, Finn JD, et al. 2001. Incidence of distal forearm fractures in British men and women. Osteoporosis Int, 12:555-58.

Orwoll ES, Oviatt SK, McClung MR, et al. 1990. The rate of bone mineral loss in normal men and the effects of calcium and cholecalciferol supplementation. Ann Int Med, 112:29-34.

Orwoll E, Ettinger M, Weiss S, et al. 2000. Alendronate treatment of osteoporosis in men. $N$ Engl J Med, 343:604-10.

Orwoll ES, Scheele WH, Paul S, et al. 2003. The effect of teriparatide [human parathyroid hormone (1-34)] therapy on bone density in men with osteoporosis. J Bone Miner Res, 18:9-17.

Pande I, Francis RM. 2001 Osteoporosis in men. Best Practice and Research in Clinical Rheumatology, 15:415-27.

Pande I., O'Neill TW, Pritchard C, et al. 2000. Bone mineral density, hip axis length and risk of hip fractures in men: results from the Cornwall hip fracture study. Osteoporosis Int, 11:866-70.

Parsons TJ, Prentice A, Smith EA, et al. 1996. Bone mineral mass consolidation in young British adults. $J$ Bone Min Res, 11:264-74.

Poor G, Atkinson EJ, Lewallen DG, et al. 1995. Age-related hip fracture in men: clinical spectrum and short-term outcome. Osteoporosis Int, 5:419-26.
Poor G, Jacobsen SJ, Melton LJ. 1994. Mortality after hip fracture. Facts and Research in Gerontology, 7:91-109.

Reginster JY, Seeman E, De Vernejoul MC, et al. 2005. Strontium ranelate reduces the risk of nonvertebral fractures in postmenopausal women with osteoporosis: Treatment of Peripheral Osteoporosis (TROPOS) study. J Clin Endocrinol Metabolism, 90:2816-22.

Reid IR, Wattie DJ, Evans MC, et al. 1996. Testosterone therapy in glucocorticoid-treated men. Arch Int Med, 156:1173-77.

Ringe JD, Dorst A, Kipshoven C, et al. 1998. Avoidance of vertebral fractures in men with idiopathic osteoporosis by a three year therapy with calcium and low-dose intermittent monofluorophosphate. Osteoporosis Int, 8:47-52.

Ringe JD, Faber H, Salem M, et al. 2004. Risedronate therapy reduces the risk of new vertebral fractures in osteoporotic men within 1 year. ASBMR, $26^{\text {th }}$ Annual Meeting, Seattle, (Abs) M424.

Rosen CJ, Bilizekian JP. 2001. Anabolic therapy for osteoporosis. J Clin Endocrinol Metab, 86:957-64.

Roy DK, O'Neill TW, Finn JD, et al. 2003. Determinants of incident vertebral fracture in men and women: results for the European Prospective Osteoporosis Study (EPOS). Osteoporosis Int, 14:19-26.

Royal College of Physicians of London. 1989. Fractured neck of femur: prevention and management. London: Royal College of Physicians of London.

Scane AC, Francis RM, Sutcliffe AM, et al. 1999. Case-control study of the pathogenesis and sequelae of symptomatic vertebral fractures in men. Osteoporosis Int, 9:91-7.

Schwartzman J, Yazicic Y, Rifkin WD, et al. 2006. Denosumab in postmenopausal women with low bone mineral density. $N$ Engl $J$ Med, 354:2390-91.

Seeman E, Melton LJIII, O'Fallon WM. 1983. Risk factors for spinal osteoporosis in men. Am J Med, 75:977-83.

Seeman E. 2001. Sexual dimorphism in skeletal size, density and strength. $J$ Clin Endocrinol Metab, 86:4576-84.

Stanley HL, Schmitt BP, Poses RM, et al. 1991. Does hypogonadism contribute to the occurrence of a minimal trauma hip fracture in elderly men? J Am Geriat Soc, 39:766-71.

Sun Y, Mao M, Sun L, et al. 2002. Treatment of osteoporosis in men using dehydroepiandrosterone sulfate. Chinese Medical Journal, 115: 402-4.

Trivedi DP, Doll R, Khaw KT, 2003. Effect of four monthly oral vitamin D3 (cholecalciferol) supplementation on fractures and mortality in men and women living in the community: randomised double blind controlled trial. BMJ, 326:469.

Trovas GP, Lyritis GP, Galanos A, et al. 2002. A randomized trial of nasal spray calcitonin in men with idiopathic osteoporosis: effects on bone mineral density and bone markers. J Bone Miner Res, 17:521-27.

Toth E, Csupor E, Meszaros S, et al. 2005. The effect of intranasal salmon calcitonin therapy on bone mineral density in idiopathic male osteoporosis without vertebral fractures- an open label study. Bone, 36:47-51.

Tuck SP, Raj N, Summers GD. 2002. Is distal forearm fracture in men due to osteoporosis? Osteoporosis Int, 13:630-6.

Tuck SP, Fordham JN. 2001. Intravenous Pamidronate for treatment of osteoporosis. Rheumatology, 40 (Suppl 1): Abstracts 268.

Tuck SP, Francis RM. 2005. Male Osteoporosis. In Arden N. Osteoporosis Illustrated, $2^{\text {nd }}$ ed. London: Remedica. p 163-84.

US Department of Health and Human Resources. 2004. Bone health and osteoporosis. A report of the surgeon general. Rockville, MD: USDHHS.

Van der Klift M, De Laet CE, McCloskey EV, et al. 2002. The incidence of vertebral fractures in men and women: the Rotterdam Study. $J$ Bone Min Res, 17:1051-6.

Van Staa TP, Dennison EM, Leufkens HGM, et al. 2001. Epidemiology of fractures in England and Wales. Bone, 29:517-22.

Varanasi SS, Francis RM, Berger CEM, et al. 1999. Mitochondrial DNA deletion associated oxidative stress and male osteoporosis. Osteoporosis Int, 10:143-9. 